\title{
Performance, Immune Responses, and Blood Biochemistry of Broiler Chickens Fed with Plant Growth Compound
}

\author{
A. Mohseni Gharechopogh ${ }^{a}$, J. Fakhraei ${ }^{\mathrm{a}, *}$, S. A. Hosseini ${ }^{\mathrm{b}}$, H. Mansoori Yarahmadia ${ }^{\text {, \& H. Lotfollahian }}{ }^{\mathrm{b}}$ \\ aDepartment of Animal Science, Islamic Azad University, Arak Branch, Arak, Iran \\ ${ }^{\mathrm{b}}$ Animal Science Research Institute of Iran (ASRI), Agricultural Research Education and Extension Organization \\ (AREEO), Karaj, Iran \\ ${ }^{*}$ Corresponding author: j-fakhraei@iau-arak.ac.ir \\ (Received 21-05-2020; Revised 05-07-2020; Accepted 03-08-2020)
}

\begin{abstract}
Today, medicinal plants and prebiotics are known as growth stimulants and can have beneficial effects on health and performance. This study was conducted to evaluate the effects of plant growth promoters and a prebiotic (lactose) on growth performance, immune responses, and blood biochemical parameters in broiler chicks. Seven hundred and fifty Arian broiler chicks (mixed-sex) were allocated to six treatments and five replicates at one day of age. Three plant-based growth promoters (ASRI1, ASRI2, and commercial supplement (Optifeed)) and two dietary prebiotic levels (0 and $1 \mathrm{~kg} /$ ton) were evaluated in a completely randomized design with $3 \times 2$ factorial arrangements. The results showed that growth performance and humoral and cellular immunities did not differ among experimental treatments; therefore, the herbal compounds ASRI1 and ASRI2 can be used as growth promoters equivalent to the commercial products currently used in the broiler chicken industry. An interaction effect of growth promoter $\times$ prebiotic was detected for concentrations of calcium in the serum. Serum calcium concentrations of birds fed ASRI 2 and $1 \mathrm{~kg} /$ ton prebiotic were greater than those of chickens receiving the commercial growth promoter. Serum triglycerides and VLDL-C concentrations were significantly lower in birds treated with ASRI1 growth promoter compared to those fed with a commercial growth promoter. In conclusion, there was no difference between ASRI1, ASRI2, and Optifeed growth promoters in their effectiveness as promoters of growth and immunity of broiler chicks.
\end{abstract}

Keywords: broiler chicks; cellular immunity; immunoglobulin; lipid profile; medicinal plants

\section{INTRODUCTION}

The prohibition in the use of antibiotic growth promoters (AGP) in animal diets (European Union Reg. no. $1831 / 2003 /$ EC) has increased animal health challenges which may lead to economic losses (Attia et al., 2015). After the prohibition, some alternatives for antibiotics such as probiotics, prebiotics, medical herbs, and essential oils have emerged (Mašek et al., 2014; Hady et al., 2013; Poorghasemi et al., 2017).

Natural compounds such as essential oils are often used in the production of some pharmaceuticals products or cosmetics as well as in the agricultural industry. Essential oils as secondary compounds in medicinal plants are known to have diverse and complex components that include aromatic compounds and terpenoids (Nazzaro et al., 2013). Medicinal plants are also known to have some antibacterial, antifungal, antiviral, antioxidant, and immunostimulatory properties (Bento et al., 2013; Krishan \& Narang, 2014). Medicinal plants are usually used to improve and increase growth and immune responses because of their antioxidant and antimicrobial properties and positive effects on the digestive system (Abdulkarimi et al., 2011; Fallah \& Mirzaei,
2016; Poorghasemi et al., 2015). The major compounds in medicinal plants and their derivatives control pathogenic bacteria, stimulate endogenous digestive enzyme activity, and increase nitrogen absorption (Sethiya, 2016). Medicinal plants can improve immune responses because they stimulate the production of immunoglobulins and lymphocytic activity and increase secretion of interferon- $\gamma$ (IFNG) by the cells of the immune systems (Krishan \& Narang, 2014; Faramarzi et al., 2013; Gopi et al., 2014). There are reports of positive effects of medicinal plants on poultry's growth and health (Karadas et al., 2014; Zeng et al., 2015). Cell walls from yeast are used extensively in poultry diets contaminated with aflatoxin in order to improve growth performances (Skalická \& Koréneková, 2016).

Prebiotics are defined as non-digestible food compounds that are known to have beneficial effects on the host by improving the growth and/or activity of one or a limited number of bacteria in the colon (Poorghasemi et al., 2017). Prebiotics are nonhydrolyzable compounds in the digestive system that benefit the host. These beneficial effects of prebiotics are to increase selective substrates for classes of commensal bacteria, induce changes in the gut microbiota, induce positive changes 
in functions of the gut and other organ systems of the host (Lotfi et al., 2019). Prebiotics can inhibit pathogen adherence and prevent colonization of bacteria by adhering to the bacteria (Lotfi et al., 2019). The inclusion of prebiotics in the diet of chickens decreases the numbers of clostridia and increases the resistance to colonization by pathogens. Prebiotics can improve the digestibility and performance parameters by providing the optimum conditions for beneficial bacteria (Ohimain \& Ofongo, 2012).

Recently, various types of oligosaccharides have been introduced as prebiotics to be used in the poultry industry (Abd-Elsamee et al., 2015). One of these oligosaccharides is lactose. Due to the lack of lactase in poultry, the digestive process of lactose in the upper gastrointestinal tract is preserved and after reaching the colon, lactose can be used as a carbohydrate substrate and it provides important sources of energy for beneficial colon bacteria that results in the production of enzymes such as beta-fructosidase, beta-glucosidase, and xylanase, or other hydrolases to increase the access of nutrients by the beneficial bacteria that eventually results in the improvement of intestinal microflora in poultry (Lotfi et al., 2019). Therefore, prebiotics and medicinal plants can have beneficial effects on performance, immune responses, and gut flora in poultry.

Since most of the feed additives used in the poultry industry in Iran are imported, this study was conducted to evaluate the effects of growth promoters in plants containing essential oils that are produced in Iran compared to currently available commercial growth promotors. The effects of these feed additives were investigated in combination with prebiotics (lactose) on immune responses, growth performance, and blood parameters in broiler chicks.

\section{MATERIALS AND METHODS}

All procedures used were approved by the ethical guidelines for animal use and animal care in the Animal Science Research Institute, Alborz Province, Iran (Directive 2010/63/EU).

\section{Experimental Design, Diets, and Housing}

A total of 750 1-day-old Arian broiler chicks (initial weight of $42 \pm 2 \mathrm{~g}$ ) were purchased from a commercial hatchery. The broiler chicks were placed in pens at the closed house system with controlled humidity and temperature. During the first week of the experiment, the temperature was maintained at $33^{\circ} \mathrm{C}$ then reduced by $2-3^{\circ} \mathrm{C}$ every week to a final temperature of $22-23^{\circ} \mathrm{C}$. Humidity was maintained between 55 and $65 \%$ by water spray. The lighting program provided $23 \mathrm{~h}$ of light and $1 \mathrm{~h}$ of dark during the experimental period. During the experiment, the experimental chickens had ad libitum access to feed and water.

A three-phase feeding program was formulated to meet Arian nutrient recommendations for starter (0-14 d), grower (15-28 d), and finisher (29-42 d) periods in poultry production (Table 1$)$. The experimental treatments were assigned in a $3 \times 2$ factorial arrangement with three plant supplements (Optifeed, ASRI1 (pomegranate hull, lemon, and thymes oil), and ASRI2 (pomegranate hull, lemon, and oregano oil) and two dietary prebiotic (lactose) levels ( 0 and $1 \mathrm{~kg} / \mathrm{ton})$. The commercial growth stimulant used in this study was a product of the French company Optifeed, which was made based on herbal extracts and derivatives from plants, especially saponin, at a rate of $1.5 \%$. The active ingredients of ASRI 1 supplement include Geraniol (0.45\%), Borneol (1.21\%), Cineol $(0.29 \%)$, and Thymol $(1.65 \%)$. The active ingredients of ASRI2 supplement include Geraniol $(0.42 \%)$, Borneol (1.14\%), Cineol (0.25\%), and Thymol (1.55\%).

Each treatment was replicated five times with 25 birds/per replicate. Crude protein was analyzed as recommended by the Association of Official Analytical Chemists (AOAC, 2005).

\section{Growth Performance}

All chickens were weighed at the beginning and at the end of each rearing period and body weight gain (BWG) was determined. Feed intake (FI) was recorded periodically and weights of dead birds were taken into

Table 1. Ingredients and nutrients in the basal diets for chickens

\begin{tabular}{lccc}
\hline Ingredients (mg) & $\begin{array}{c}\text { Starter } \\
(1-14 \text { day })\end{array}$ & $\begin{array}{c}\text { Grower } \\
(15-28 \text { day })\end{array}$ & $\begin{array}{c}\text { Finisher } \\
(29-42 \text { day })\end{array}$ \\
\hline Corn, $80 \mathrm{~g} \mathrm{CP} / \mathrm{kg}$ & 518.4 & 582.3 & 600.2 \\
Soybean oil & 35.4 & 42.6 & 32.2 \\
Soybean meal, $440 \mathrm{~g}$ & 383.6 & 291.0 & 331.0 \\
$\mathrm{CP} / \mathrm{kg}$ & 3.50 & 3.1 & 2.5 \\
DL-Methionine & 2.5 & 1.5 & 1.4 \\
L-Lysine HCl & 1.00 & 0.00 & 1.4 \\
L-Threonine & 18.0 & 9.7 & 14.3 \\
Limestone & 21.1 & 50.0 & 0.00 \\
Fish meal & 2.50 & 2.5 & 3.0 \\
NaCl & 2.50 & 2.5 & 2.5 \\
Vitamin premix & 2.50 & 2.5 & 2.5 \\
Mineral premix & 9.00 & 12.3 & 9.0 \\
Dicalcium phosphate & 1000 & 1000 & 1000 \\
Total & & & \\
Calculated values (g/kg) & & & \\
Metabolizable energy & 3025.0 & 3100.0 & 3200.0 \\
(kcal/kg) & & & \\
Crude protein & 231.2 & 213.0 & 193.0 \\
Digestible Lysine & 14.4 & 12.4 & 10.9 \\
Digestible Methionine & 5.10 & 4.5 & 4.1 \\
Calcium & 10.5 & 9.0 & 8.5 \\
Available phosphorus & 5.00 & 4.5 & 4.2 \\
Sodium & 1.60 & 1.8 & 1.7 \\
Chloride & 1.90 & 1.7 & 1.6 \\
\hline
\end{tabular}

Note: aVitamin premix provided per kilogram of diet (vitamin A (retinyl acetate $)=15,000 \mathrm{IU}$; vitamin D3= 5,000 IU; vitamin E (DL- $\alpha$ tocopherol acetate $)=80 \mathrm{mg}$; vitamin $\mathrm{K}=5 \mathrm{mg}$; thiamin $=3 \mathrm{mg}$; riboflavin $=10 \mathrm{mg}$; pyridoxine $=5 \mathrm{mg}$; vitamin $\mathrm{B} 12=0.02 \mathrm{mg}$; niacin= $70 \mathrm{mg}$; choline chlorid $=350 \mathrm{mg}$; folic acid $=2 \mathrm{mg}$; biotin= $0.4 \mathrm{mg}$; pantothenic acid= $20 \mathrm{mg}$ ).

${ }^{b}$ Mineral premix provided per kilogram of diet (Mn (manganese sulphate $=100 \mathrm{mg} ; \mathrm{Zn}$ (zinc sulphate) $=65 \mathrm{mg} ; \mathrm{Cu}$ (copper sulphate $)=5 \mathrm{mg}$; Se $($ sodium selenite $)=0.22 \mathrm{mg}$; (calcium iodate $)=$ $0.5 \mathrm{mg}$; and $\mathrm{C}=0.5 \mathrm{mg}$ ). 
account. Feed conversion ratio (FCR) was calculated for starter, grower, and finisher periods by dividing FI by BWG (Poorghasemi et al., 2013).

\section{Cellular Immunity}

On the $25^{\text {th }}$ day of the experiment, $0.1 \mathrm{~mL}$ of dinitrochlorobenzene (DNCB) and phytohemagglutinin (PHA) was administered to 2 chicks per cage. One area of $10 \mathrm{~cm}^{2}$ was allocated for administering DNCB. Skin thickness was assessed before sensitization. The broiler chicks were sensitized with DNCB at a dose of $0.1 \mathrm{~mL}$ per $\mathrm{cm}^{2}$ area. Skin thickness was evaluated at different sites in this area at 24 and $48 \mathrm{~h}$ after the DNCB challenge. Also, $0.1 \mathrm{~mL}$ of PHA $\left(10 \mathrm{mg} / \mathrm{mL}^{-1}\right.$ acetone and olive oil in a 4:1 ratio) was administered intradermally between the third and fourth digits of the right foot and the area thickness was evaluated 24 and $48 \mathrm{~h}$ after administration using a constant tension micrometer (Cai et al., 2012).

\section{Humoral Immunity}

At the end of the $5^{\text {th }}$ week of the experiment, $3 \mathrm{~mL}$ of a 5\% suspension of sheep red blood cells (SRBCs) was administered intravenously to two birds per replicate. Blood samples were collected 1 week after administration. The blood samples were centrifuged in $1800 \mathrm{x} \mathrm{g}$ for $15 \mathrm{~min}$ and the serum was collected and stored in $-20^{\circ} \mathrm{C}$ for subsequent analyses. Complement in each serum sample was inactivated by heating to $56^{\circ} \mathrm{C}$ for $30 \mathrm{~min}$ and then analyzed for total anti-SRBC antibodies by using the protocol described by Delhanty \& Solomon (1966). Briefly, each inactivated serum sample was titrated in order to evaluate the total and mercaptoethanol (ME)-resistant (IgG) anti-SRBC antibody titers. ME-sensitive (IgM) antibody titers were obtained by subtracting the titer for IgG antibodies from the total antibodies. All the data for antibody titers are reported in terms of $\log _{2}$ (Poorghasemi et al., 2015).

\section{Blood Variables}

At the end of the experiment, a $2.5 \mathrm{~mL}$ of blood sample was taken from two birds in each replicate and centrifuged at $3000 \times \mathrm{g}$ for $15 \mathrm{~min}$ and the serum was collected. Serum concentrations of calcium, phosphorous, protein, albumin, globulin, cholesterol, triglyceride, HDL-C, LDL-C, and VLDL-C were determined using commercial kits from Pars Azmun (Tehran-Iran) according to the manufacturer's recommendations.

The CPC Photometric method was used to measure calcium. In this method, the calcium ion with orthocresolphthalein complex one in the alkaline environment creates a purple color complex and the intensity of which is proportional to the amount of serum calcium. Color stability occurs within 30 minutes and the reaction intensity is read at the wavelength of $545 \mathrm{~nm}$ (Badiei et al., 2011).

Phosphorus was measured using Phosphomolybdate/uv. The phosphorus in the serum reacts with ammonium molybdate in an acidic environment and creates the blue color of hetero molybdenum, and the intensity of which is proportional to the amount of phosphorus in the sample. Color stability was established within 10 minutes, and the reaction intensity was read at a wavelength of $340 \mathrm{~nm}$ (Badiei et al., 2011).

The total serum protein and total serum albumin were measured using a photometric method at a wavelength of $546 \mathrm{~nm}$. The amount of globulin was calculated by subtracting the total protein from total serum albumin (Mehrabi et al., 2011).

Cholesterol, triglycerides, and HDL-C in the serum samples were estimated using enzymatic CHOD-PAP method at the wavelength of $546 \mathrm{~nm}$ (Baighi \& Nobakht, 2017).

The LDL-C and VLDL values were obtained by the following formula (Friedewald et al., 1972):

LDL-C $=$ total cholesterol - HDL-C - (triglycerides/5)

$\mathrm{VLDL}=$ plasma triglycerides $/ 5$

\section{Statistical Analyses}

This study was conducted as a completely randomized design with $2 \times 3$ factorial arrangement for assessing the effects of growth promoters and prebiotic. Data were analyzed for the main effects of growth promoter and prebiotic and their interaction. The statistical model used was represented by the equation:

$$
\text { Yijk }=\mu+(G i)+(P j)+(G P i j)+(\text { eijk })
$$

where Yijk is the individual observation, $\mu$ is the overall mean, $(\mathrm{Gi})$ is the main effect of the growth promoter, $(\mathrm{Pj})$ is the main effect of the prebiotic, (GPij) is the interaction between growth promoter and prebiotic, and (eijk) is the residual error. Data were analyzed using the General Linear Model procedure of SAS. The Tukey test was used to detect differences $(p<0.05)$ among group means $(\mathrm{p} \leq 0.05)$.

\section{RESULTS}

\section{Growth Performance}

The data for growth performance of experimental broiler chicks are summarized in Table 2. Body weight, feed intake, and feed conversion ratio were not influenced by the growth promoter, prebiotic, and interaction of growth promoter and prebiotic $(\mathrm{p}>0.05)$.

Body weight and feed conversion ratio in the treatments using a combination of ASRI1 and ASRI2 with prebiotics were higher than treatments without the prebiotic. However, the use of prebiotics alone did not increase body weight. The highest body weight at the end of the experimental period was found in the chicks treated with ASRI1 in combination with prebiotics and the lowest was found in the chicks treated with ASRI2 without prebiotics. In addition, the lowest conversion ratio at 42 days of age was found in the chicks treated with ASRI1 in combination with prebiotics.

The use of ASRI1 in combination with prebiotics was able to increase feed intake compared to experimental chickens treated with commercial growth promoters (Optifeed) and ASRI2 in combinations with prebiotics. 
The highest feed intake at 42 days of age was found in the experimental chicks treated with commercial growth promoter (Optifeed) without prebiotic treatment and the lowest feed intake was found in the experimental chicks treated with ASRI2 in combination with prebiotics.

\section{Immunity}

Our data for cellular and humoral immunities are summarized in Table 3. Results indicated that the inclusion of prebiotic and growth promoters in the diet did

Table 2. Growth performance of broiler chicks at 42-days-of-age fed containing growth promoter

\begin{tabular}{|c|c|c|c|c|}
\hline \multirow{2}{*}{ Growth promoter } & \multicolumn{4}{|c|}{ Variables } \\
\hline & Prebiotic & Body weight (g/bird) & Feed intake (g/bird) & Feed conversion ratio \\
\hline \multirow[t]{2}{*}{ Optifeed } & 0.00 & 2113.00 & 3784.00 & 1.71 \\
\hline & 1.00 & 2078.00 & 3660.00 & 1.76 \\
\hline \multirow[t]{2}{*}{ ASRI1 } & 0.00 & 2163.00 & 3680.00 & 1.70 \\
\hline & 1.00 & 2175.00 & 3696.00 & 1.69 \\
\hline \multirow[t]{2}{*}{ ASRI2 } & 0.00 & 2061.00 & 3636.00 & 1.76 \\
\hline & 1.00 & 2065.00 & 3575.00 & 1.73 \\
\hline SEM & & 56.84 & 82.36 & 0.039 \\
\hline \multicolumn{5}{|l|}{ Growth promoter } \\
\hline Optifeed & & 2145.00 & 3722.00 & 1.738 \\
\hline ASRI1 & & 2169.00 & 3688.00 & 1.702 \\
\hline ASRI2 & & 2063.00 & 3605.00 & 1.750 \\
\hline SEM & & 40.80 & 59.29 & 0.028 \\
\hline \multicolumn{5}{|l|}{ Prebiotic } \\
\hline 0.00 & & 2146.00 & 3700.00 & 1.727 \\
\hline 1.00 & & 2106.00 & 3644.00 & 1.733 \\
\hline SEM & & 33.30 & 48.40 & 0.023 \\
\hline \multicolumn{5}{|l|}{ P-value } \\
\hline Growth promoter & & 0.644 & 0.377 & 0.463 \\
\hline Prebiotic & & 0.844 & 0.420 & 0.864 \\
\hline Growth promoter $\times$ Prebiotic & & 0.528 & 0.412 & 0.525 \\
\hline
\end{tabular}

Note: SEM= Standard error of means; ASRI1: pomegranate hull, lemon, and thymes oil; ASRI2: pomegranate hull, lemon, and oregano oil.

Table 3. Cellular and humoral immunities of broiler chicks at 42-days-of-age fed containing growth promoter

\begin{tabular}{|c|c|c|c|c|c|c|c|c|}
\hline \multirow{2}{*}{ Growth promoter } & \multirow{2}{*}{ Prebiotic } & SRBC & $\mathrm{IgG}$ & IgM & PHA-24 & PHA-48 & DNCB-24 & DNCB-48 \\
\hline & & \multicolumn{3}{|c|}{$\log 2$} & \multicolumn{4}{|c|}{$\mathrm{mm}$} \\
\hline \multirow[t]{2}{*}{ Optifeed } & 0.00 & 5.75 & 3.75 & 2.00 & 1.27 & 1.01 & 1.53 & 0.960 \\
\hline & 1.00 & 5.75 & 4.25 & 1.50 & 1.33 & 0.980 & 1.30 & 0.901 \\
\hline \multirow[t]{2}{*}{ ASRI1 } & 0.00 & 5.25 & 3.37 & 1.87 & 1.26 & 0.920 & 1.18 & 0.870 \\
\hline & 1.00 & 5.25 & 3.75 & 1.50 & 1.32 & 1.07 & 1.50 & 1.08 \\
\hline \multirow[t]{2}{*}{ ASRI2 } & 0.00 & 6.00 & 4.25 & 1.75 & 1.20 & 1.09 & 1.25 & 1.04 \\
\hline & 1.00 & 5.62 & 4.00 & 1.62 & 1.50 & 0.94 & 1.40 & 0.92 \\
\hline SEM & & 0.404 & 0.377 & 0.316 & 0.110 & 0.090 & 0.140 & 0.069 \\
\hline \multicolumn{9}{|l|}{ Growth promoter } \\
\hline Optifeed & & 5.75 & 4.00 & 1.75 & 1.421 & 0.939 & 1.305 & 1.00 \\
\hline ASRI1 & & 5.25 & 3.56 & 1.68 & 1.345 & 0.976 & 1.297 & 0.999 \\
\hline ASRI2 & & 5.81 & 4.12 & 1.68 & 1.326 & 0.981 & 1.357 & 1.021 \\
\hline SEM & & 0.293 & 0.272 & 0.219 & 0.096 & 0.044 & 0.073 & 0.065 \\
\hline \multicolumn{9}{|l|}{ Prebiotic } \\
\hline 0.00 & & 5.66 & 3.79 & 1.87 & 1.323 & 0.957 & 1.251 & 1.013 \\
\hline 1.00 & & 5.54 & 4.00 & 1.54 & 1.405 & 0.974 & 1.389 & 1.001 \\
\hline SEM & & 0.240 & 0.233 & 0.189 & 0.079 & 0.036 & 0.059 & 0.053 \\
\hline \multicolumn{9}{|l|}{ P-value } \\
\hline Growth promoter & 0.341 & 0.319 & 0.973 & 0.764 & 0.760 & 0.819 & 0.965 & \\
\hline Prebiotic & & 0.714 & 0.511 & 0.195 & 0.472 & 0.735 & 0.118 & 0.876 \\
\hline Growth promoter $\times$ Prebiotic & 0.873 & 0.585 & 0.828 & 0.148 & 0.060 & 0.421 & 0.302 & \\
\hline
\end{tabular}

Note: SRBC= suspension of sheep red blood cells; Ig= Immunoglobulin G; IgM= Immunoglobulin M; PHA-24= phytohemagglutinin-24 h; PHA-48= phytohemagglutinin-48 h; DNCB-24= dinitrochlorbenzene- $24 \mathrm{~h}$; DNCB-48= dinitrochlorbenzene-48 h; ASRI1: pomegranate hull, lemon, and thymes oil; ASRI2: pomegranate hull, lemon, and oregano oil SEM= Standard error of means. 
not have significant effects on the cellular and humoral immunities. These results indicate that the herbal compounds of ASRI1 and ASRI2 have growth promoter activities that are similar to those of commercial growth promoters (Optifeed) and can be used as a growth promoter in the broiler industry.

The highest responses to SRBC and IgG were found in the chicks treated with ASRI2 without prebiotics. In addition, the highest level of $\operatorname{IgM}$ was found in the chicks treated with commercial growth promoter (Optifeed) without prebiotics.

The highest response to phytohemagglutinin was observed 24 hours after injection in the control chicks and the lowest was found in the chicks treated with ASRI2 without prebiotics. In addition, the highest response to phytohemagglutinin was observed 48 hours after injection in the chicks treated with ASRI2 without prebiotics and the lowest response was found in the chicks treated with ASRI1 without prebiotics. The highest response to DNCB was observed 24 hours after injection in the control chicks without treatment with growth promoter and prebiotic and the chicks treated with commercial growth promoter (Optifeed) without prebiotics. The lowest response to DNCB 24 hours after injection was observed in the chicks treated with ASRI1 without prebiotics. In addition, the highest response to DNCB was observed 48 hours after injection in the chicks treated with ASRI1 in combination with prebiotics and the lowest was observed in the chicks treated with ASRI1 without prebiotics.

\section{Blood Variables}

The effects of experimental treatments on biochemical parameters in the blood are summarized in Tables 4 and 5. Serum concentrations of globulin, albumin, protein, and phosphorous were not influenced by the experimental treatments of growth promoters and prebiotics $(p>0.05)$. However, the interaction of growth promoter $\times$ prebiotic was detected to significantly affect the serum calcium concentrations $(p<0.05)$. Serum calcium concentrations of experimental birds treated with ASRI2 and $1 \mathrm{~kg}$ /ton prebiotic were greater than those of chickens treated with commercial growth promoter (Optifeed) $(\mathrm{p}<0.05)$.

The concentrations of cholesterol, HDL-C, LDL-C, LDL/HDL, and cholesterol/HDL ratios were not affected by the experimental treatments of growth promoter and prebiotics $(p>0.05)$. However, serum concentrations of triglycerides and VLDL-C were lower $(p<0.05)$ in birds treated with the ASRI1 compared with those fed commercial growth promoters (Optifeed).

\section{DISCUSSION}

\section{Growth Performance}

Growth performance is one general and direct criterion in the poultry industry because it greatly affects cost and profitability of the poultry enterprise (Ajuwon, 2015). Results of the present study revealed that inclu-

Table 4. Blood variables of broiler chicks at 42-days-of-age fed containing growth promoter

\begin{tabular}{|c|c|c|c|c|c|c|}
\hline \multirow{2}{*}{ Growth promoter } & \multirow{2}{*}{ Prebiotic } & Calcium & Phosphorous & Protein & Albumin & Globulin \\
\hline & & \multicolumn{2}{|c|}{$\mathrm{mg} / \mathrm{dL}$} & \multicolumn{3}{|c|}{$\mathrm{g} / \mathrm{dL}$} \\
\hline \multirow[t]{2}{*}{ Optifeed } & 0.00 & $9.88^{\mathrm{b}}$ & 11.62 & 3.25 & 1.35 & 1.90 \\
\hline & 1.00 & $10.61^{\mathrm{ab}}$ & 10.82 & 3.50 & 1.45 & 2.05 \\
\hline \multirow[t]{2}{*}{ ASRI1 } & 0.00 & $10.54^{\mathrm{ab}}$ & 11.62 & 3.25 & 1.37 & 1.87 \\
\hline & 1.00 & $10.47^{\mathrm{ab}}$ & 10.82 & 3.00 & 1.27 & 1.72 \\
\hline \multirow[t]{2}{*}{ ASRI2 } & 0.00 & $10.34^{\mathrm{ab}}$ & 14.02 & 3.25 & 1.35 & 1.90 \\
\hline & 1.00 & $11.01^{\mathrm{a}}$ & 10.40 & 3.50 & 1.45 & 2.05 \\
\hline SEM & & 0.217 & 1.61 & 0.225 & 0.095 & 0.200 \\
\hline \multicolumn{7}{|l|}{ Growth promoter } \\
\hline Optifeed & & 10.24 & 11.22 & 3.37 & 1.40 & 1.97 \\
\hline ASRI1 & & 10.51 & 12.82 & 3.12 & 1.32 & 1.80 \\
\hline ASRI2 & & 10.67 & 10.70 & 3.37 & 1.40 & 1.97 \\
\hline SEM & & 0.165 & 1.22 & 0.172 & 0.072 & 0.153 \\
\hline \multicolumn{7}{|l|}{ Prebiotic } \\
\hline 0.00 & & $10.25^{\mathrm{b}}$ & 11.21 & 3.25 & 1.35 & 1.89 \\
\hline 1.00 & & $10.70^{\mathrm{a}}$ & 11.95 & 3.33 & 1.39 & 1.94 \\
\hline SEM & & 0.135 & 0.001 & 0.14 & 0.059 & 0.125 \\
\hline \multicolumn{7}{|l|}{ P-value } \\
\hline Growth promoter & 0.210 & 0.458 & 0.507 & 0.704 & 0.652 & \\
\hline Prebiotic & & 0.032 & 0.611 & 0.679 & 0.695 & 0.870 \\
\hline Growth promoter $\times$ Prebiotic & 0.019 & 0.658 & 0.507 & 0.541 & 0.729 & \\
\hline
\end{tabular}

Note: Means in the same column with different superscripts differ significantly $(p<0.05)$. ASRI1= pomegranate hull, lemon, and thymes oil; ASRI2= pomegranate hull, lemon, and oregano oil; SEM= Standard error of means. 
Table 5. Lipid profile in serum of broiler chicks at 42-days-of-age fed containing growth promoter

\begin{tabular}{|c|c|c|c|c|c|c|c|c|}
\hline \multirow[b]{2}{*}{ Growth promoter } & \multicolumn{8}{|c|}{ Variables } \\
\hline & Prebiotic & $\begin{array}{c}\text { Cholesterol } \\
\text { (mg/dL) }\end{array}$ & $\begin{array}{l}\text { Triglycerides } \\
\text { (mg/dL) }\end{array}$ & $\begin{array}{l}\text { HDL-C } \\
(\mathrm{mg} / \mathrm{dL})\end{array}$ & $\begin{array}{l}\text { LDL-C } \\
\text { (mg/dL) }\end{array}$ & $\begin{array}{l}\text { VLDL-C } \\
(\mathrm{mg} / \mathrm{dL})\end{array}$ & $\begin{array}{l}\text { LDL/ } \\
\text { HDL }\end{array}$ & $\begin{array}{c}\text { Cholesterol/ } \\
\text { HDL }\end{array}$ \\
\hline \multirow[t]{2}{*}{ Optifeed } & 0.00 & 110.50 & 112.25 & 31.50 & 56.55 & 22.45 & 1.81 & 3.56 \\
\hline & 1.00 & 124.25 & 113.25 & 33.62 & 67.97 & 22.65 & 2.04 & 3.72 \\
\hline \multirow[t]{2}{*}{ ASRI1 } & 0.00 & 106.25 & 91.50 & 35.00 & 52.95 & 18.30 & 1.52 & 3.05 \\
\hline & 1.00 & 93.00 & 82.25 & 38.75 & 37.80 & 16.45 & 1.09 & 2.55 \\
\hline \multirow[t]{2}{*}{ ASRI2 } & 0.00 & 115.00 & 107.50 & 40.87 & 52.62 & 21.50 & 1.38 & 2.92 \\
\hline & 1.00 & 124.25 & 90.25 & 31.87 & 74.32 & 18.05 & 2.44 & 4.03 \\
\hline SEM & & 9.22 & 9.09 & 4.07 & 8.76 & 1.82 & 0.294 & 0.348 \\
\hline \multicolumn{9}{|l|}{ Growth promoter } \\
\hline Optifeed & & 117.37 & $112.75^{\mathrm{a}}$ & 32.56 & 62.26 & $22.55^{\mathrm{a}}$ & 1.93 & 3.64 \\
\hline ASRI1 & & 99.62 & $86.67 \mathrm{~b}$ & 36.87 & 45.37 & $17.37 \mathrm{~b}$ & 1.30 & 2.80 \\
\hline ASRI2 & & 119.62 & $98.87^{\mathrm{ab}}$ & 36.37 & 63.34 & $19.77^{\mathrm{ab}}$ & 1.91 & 3.48 \\
\hline SEM & & 6.78 & 6.59 & 2.78 & 6.30 & 1.32 & 0.213 & 0.255 \\
\hline \multicolumn{9}{|l|}{ Prebiotic } \\
\hline 0.00 & & 110.58 & 103.75 & 35.79 & 54.04 & 20.75 & 1.57 & 3.18 \\
\hline 1.00 & & 111.83 & 95.25 & 34.75 & 60.03 & 19.05 & 1.85 & 3.43 \\
\hline SEM & & 5.542 & 5.3387 & 0.207 & 5.14 & 0.077 & 0.17 & 0.208 \\
\hline \multicolumn{9}{|l|}{ P-value } \\
\hline Growth promoter & 0.102 & 0.041 & 0.501 & 0.104 & 0.041 & 0.089 & 0.069 & \\
\hline Prebiotic & & 0.683 & 0.279 & 0.750 & 0.421 & 0.279 & 0.267 & 0.395 \\
\hline Growth promoter $\times$ Prebiotic & 0.343 & 0.626 & 0.238 & 0.131 & 0.626 & 0.072 & 0.109 & \\
\hline
\end{tabular}

Note: Means in the same column with different superscripts differ significantly $(\mathrm{p}<0.05)$. HDL-C $=$ high-density lipoprotein-cholesterol; LDL-C $=$ lowdensity lipoprotein-cholesterol; VLDL-C= very low-density lipoprotein-cholesterol; LDL/HDL= LDL to HDL rasio; ASRI1= pomegranate hull, lemon, and thymes oil; ASRI2= pomegranate hull, lemon, and oregano oil; SEM= Standard error of means.

sion of prebiotic and herbal-based growth promoters in the diet did not have significant differential effects on growth performance compared to commercial growth promoters. This result indicates that ASRI1 and ASRI2 are as effective as the imported Optifeed as dietary supplements for chickens. It has been reported that dietary inclusion of thyme essential oil improved average daily gain of broiler chicks (Pournazari et al., 2017) and that essential oils improved growth performance and functions of the digestive system in animals (Simitzis, 2017). Further, inclusion of thyme essential oil in the diet improved growth performance in broiler chicks reared under hot conditions (Attia et al., 2017). Therefore, herbal supplements seem to improve growth performance under various environmental conditions. The conflict between findings in the present study and those of others may be attributed to differences in feed ingredients, physiological conditions of animals, or physical-form structure of herbal supplements from medicinal plants (powder, essential oil, and extract). Huang et al. (2015) showed that dietary inclusion of inulin prebiotic at 5-10 $\mathrm{g} / \mathrm{kg}$ increased feed intake in the starter period (0-21 d), but did not have any effect on feed intake in 42 day-old broiler chickens (Huang et al., 2015). Dietary inclusion of prebiotics into the diets of broiler chickens has been reported to increase body weight gain and feed conversion ratios (Baurhoo et al., 2007; Sims et al., 2004).

In the present study, it was observed that the use of ASRI1 and ASRI2 with prebiotics increased weight gain and feed intake and also improved feed effi- ciency, which is consistent with the results reported by Tiihonen et al. (2010).

Tiihonen et al. (2010) observed that the use of herbal medicines in the diet increased the body weight of broilers by $3 \%$ at 42 days of age. The effect of herbal ingredients may be related to the stimulations of appetite and secretions of digestive substances, increases of utilization of feeds that eventually increases growth, and antibacterial effects that are among the mechanisms that can be considered to justify the improvement of performance (Tiihonen et al., 2010). It is also suggested that herbal ingredients can improve feed conversion ratio via better use of nutrients in the feed by enhancing the activities of digestive enzymes, and better digestion in ileum confirms this idea (Tiihonen et al., 2010). The amounts and types of prebiotics fed may account for difference between our findings and those from previous studies.

\section{Immunity}

Immune responses were not influenced by experimental treatments in our study. Natural products have often been used to stimulate the immune system. Herbal plants are known to have stimulatory effects on the immune system of animals through their secondary metabolites (Hashemi et al., 2008). Talazadeh \& Mayahi (2017) showed that supplementing the diet with thyme extract in drinking water improved immune responses in broiler chicks (Talazadeh \& Mayahi, 2017). Plant de- 
rivatives are commonly used in animal nutrition and are applied as promoters of growth and immune responses due to their antioxidant, antimicrobial properties, and beneficial effects on digestion (Assiri et al., 2016; Fallah \& Mirzaei, 2016). With regards to prebiotics, there are some studies reporting that supplementation of diet with prebiotics improve concentrations of $\operatorname{IgM}$ and IgG in the circulation, cecum IgA concentration, the expression of mucin mRNA, and activities of the intestinal immune system (Huang et al., 2015; Janardhana et al., 2009). Improved immune response by inclusion of a prebiotic in the diet can be attributed to preferential colonization of the gut by the beneficial bacteria and microbial products that improve the functions of immune cells (Janardhana et al., 2009).

According to the results of the present experiment, the effects of combined uses of herbal growth stimulants and prebiotics improve the performance of the immune system, which is consistent with the results reported by Ghalamkari et al. (2011) and Houshmand et al. (2012). They state that one of the factors contributing to the improved immune response is the proper growth of lymphoid organs and the subsequent increase in antibody response having a positive correlation with the development of immune system. Their results show that in addition to genetic factors, non-genetic factors such as nutritional supplements in the diet which affect growth can change or modify the expression of the genes responsible for the development of immunity by changing the volume of antibody production and maturation of the immune system. Herbal medicines and prebiotics are among the growth supplements being used recently in poultry diets, which control harmful bacteria in the intestine and increase the function of the digestive system for better absorption of the nutrients in the diet. Herbal medicines also stimulate the growth of cells resulting in increased immune compounds (Ghalamkari et al., 2011; Houshmand et al., 2012).

\section{Blood Variables}

Blood parameters are indicative of the metabolic and health status of animals. It is well known that changes in the abundance of albumin in the blood reflect changes in liver function. While the liver is the source of albumin production, immunoglobulins are synthesized in lymphatic tissues (Jones \& Bark, 1979). Zhu et al. (2014) report that dietary inclusion of thyme essential oil significantly increases the levels of total proteins and globulins in 21-day-old chicks and significantly reduce the albumin to globulin ratio in chicks between 21 and 42 days of age.

As can be seen in the results of the present study, the amount of protein, albumin, and globulin in the chicks treated with ASRI2 and Optifeed were higher compared to the other treatments, which are consistent with the results reported by Rahimi et al. (2011).

Higher concentrations of total serum protein, albumin, and globulin under the influence of ASRI2 and Optifeed treatments in the present experiment can be associated with the increased nutrient intake, including protein, and its presence in the blood serum.
Supplementation of herbal preparations with growth stimulant activities in the diet will reduce the population of harmful microbes in the gastrointestinal tract that will reduce amino acid degradation in the digestive tract that results in greater absorption of amino acids and improves digestion and absorption of nutrients and proteins that eventually causes an increase in the concentrations of total serum protein, albumin, and globulin (Rahimi et al., 2011).

The results also showed that the serum concentration of calcium in the chicks treated with ASRI2 and prebiotics significantly increased compared to the other treatments. Limited researches have been done on the effects of prebiotics and herbal compounds on the serum calcium concentration in the broilers, but some studies have found that anorexia results in an energy deprivation which results in the decreased cellular calcium homeostasis, followed by the destruction of cell membrane integrity that ultimately reduces the functions of the cell. Reduced feed intake and decreased activity of the parathyroid gland as well as decreased parathyroid secretion, will impair renal and intestinal calcium absorption. Since herbal growth stimulants and prebiotics improve the environment of the digestive system that will produce the better absorptions of minerals and nutrients from the digested diet by increasing feed intake and providing a suitable environment for the activity of beneficial bacteria in the intestine with the final result of increased calcium absorption (Rahimi et al., 2011; Hayati et al., 2019).

Souri et al. (2015) reported that the addition of medicinal plants in the diet of broiler chickens reduced plasma triglycerides concentrations due to the presence of granuloma, cineole, citral, and borneol compounds. This reduction may be related to the decreased lipid intake or high lipid catabolism or a decrease in the activity of the acetyl coenzyme A carboxylase resulting in a decrease in esterification reactions that ultimately decreases in triacylglycerol synthesis.

Other research has shown that different compounds of herbal medicines, including citral and borneol, reduce the activity of HMG-COA in hepatic reductase. For every 5\% inhibition of the activity of the enzyme HMG-COA reductase (the key enzyme in cholesterol synthesis), cholesterol production is reduced by $2 \%$, resulting in lower cholesterol, LDL, and VLDL concentrations in the blood (Ghazvinian et al., 2018).

Serum concentrations of triglycerides and VLDL-C were significantly lower in chickens treated with ASRI1 growth promoters compared with those treated with commercial growth promoters (Optifeed). It seems that the ASRI1 growth promoter improves some parameters of lipids because of higher active substances (Geraniol, Borneol, and Cineol).

\section{CONCLUSION}

Growth promoters and prebiotic did not have a significant effect on immunity variables and growth performance in the present study. Growth promoters had a significant increase on the serum concentration of calcium and a significant decrease on serum concentra- 
tion of VLDL-C. Overall, the findings from this study indicate that the ASRI1 (pomegranate hull, lemon, and thymes oil), and ASRI2 (pomegranate hull, lemon, and oregano oil) herbal compounds are as effective as the commercially available imported growth promoter (Optifeed) and can be used as effective growth promoters in the broiler industry.

\section{CONFLICT OF INTEREST}

The authors declared that there is no conflicts of interest regarding this paper.

\section{ACKNOWLEDGEMENT}

Our special thanks to Azad University of Arak and the Animal Science Research Institute of Karaj for providing facilities and their assistance throughout the experiments

\section{REFERENCES}

Abd-Elsamee, L.D., I. EI-Wardany, N. G. Ali, \& O. M. AboEl-Azab. 2015. Supplemental chromium yeast and/or mannan oligosaccharides in growing quail diets. Iranian J. Appl. Anim. Sci. 5: 197-202.

Abdulkarimi, R., M. Daneshyar, A. Aghazadeh. 2011. Thyme (Thymus vulgaris) extract consumption darkens liver, lowers blood cholesterol, proportional liver and abdominal fat weights in broiler chickens. Ital. J. Anim. Sci. 10: 101-105. https://doi.org/10.4081/ijas.2011.e20

Ajuwon, K. M. 2015. Toward a better understanding of mechanisms of probiotics and prebiotics action in poultry species. J. Appl. Poult. Res. 25: 277-283. https://doi.org/10.3382/ japr/pfv074

AOAC. 2005. Official Methods of Analysis of AOAC International. 18th ed. Assoc. Off. Anal. Chem., Arlington.

Assiri, A. M., K. Elbanna, H. H. Abulreesh, \& M. F. Ramadan. 2016. Bioactive compounds of cold-pressed thyme (Thymus vulgaris) oil with antioxidant and antimicrobial properties. J. Oleo Sci. 65: 629-640. https://doi.org/10.5650/jos.ess16042

Attia, Y. A., A. A. Bakhashwain, \& N. K. Bertu. 2017. Thyme oil (Thyme vulgaris) as a natural growth promoter for broiler chickens reared under hot climate. Ital. J. Anim. Sci. 16: 275-282. https://doi.org/10.1080/1828051X.2016.1245594

Attia, Y. A., R. S. Hamed, A. A. El-Hamid, H. A. Shahba, \& F. Bovera. 2015. Effect of inulin and mannan-oligosaccharides compared with zinc-bacitracin on growing performance, nutrient digestibility and hematological profiles of growing rabbits. Anim. Prod. Sci. 55: 80-86. https://doi. org/10.1071/AN13286

Badiei, K., K. Mostaghni, M. Pourjafar, M. Ghane, \& E. Mohammadi. 2011. Serum thyroid hormones and trace element concentrations in crossbred Holstein cattle naturally infected with Theileria annulata. Compar. Haematol. Int. 20: 115-20. https://doi.org/10.1007/s00580-010-0962-0

Baighi, G. F. \& A. Nobakht. 2017. The effects of different levels of saturated and unsaturated fats and their composition in growing and finishing periods on productive performance and blood lipids of broilers. Iranian J. Appl. Anim. Sci. 7: 329-336.

Baurhoo, B., A. Letellier, X. Zhao, \& C. A. Ruiz-Feria. 2007. Cecal populations of lactobacilli and bifidobacteria and Escherichia coli populations after in vivo Escherichia coli challenge in birds fed diets with purified lignin or mannanoligosaccharides. Poult. Sci. 86: 2509-2516. https://doi. org/10.3382/ps.2007-00136
Bento, M. H., A. C. Ouwehand, K. Tiihonen, S. Lahtinen, P. Nurminen, M. T. Saarinen, H. Schulze, T. Mygind, \& J. Fischer. 2013. Essential oils and their use in animal feeds for monogastric animals-Effects on feed quality, gut microbiota, growth performance and food safety: a review. Vet. Med. 58: 449-458. https://doi.org/10.17221/7029-VETMED

Cai, S. J., C. X. Wu, L. M. Gong, T. Song, H. Wu, \& L. Y. Zhang. 2012. Effects of nano-selenium on performance, meat quality, immune function, oxidation resistance, and tissue selenium content in broilers. Poult. Sci. 91: 2532-2539. https:// doi.org/10.3382/ps.2012-02160

Delhanty, J. J. \& J. B. Solomon. 1966. The nature of antibodies to goat erythrocytes in the developing chicken. Immunol. 11: 103-113.

Fallah, R. \& E. Mirzaei. 2016. Effect of dietary inclusion of turmeric and thyme powders on performance, blood parameters and immune system of broiler chickens. Livest. Sci. 7: $180-186$.

Faramarzi, S., M. H. Bozorgmehrifard, A. Khaki, H. Moomivand, M. S. Ezati, S. Rasoulinezhad, A. J. Bahnamiri, \& B. R. Dizaji. 2013. Study on the effect of Thymus vulgaris essential oil on humoral immunity and performance of broiler chickens after La Sota vaccination. Ann. Biol. Res. 4: 290-294.

Friedewald, W. T, R. I. Levy, \& D. S. Fredrickson. 1972. Estimation of the concentration of LDL-C in plasma without use of the preparative ultracentrifuge. Clin. Chem. 18: 499-502. https://doi.org/10.1093/clinchem/18.6.499

Ghalamkari, G. H., M. Toghyani, E. Tavalaeian, N. Landy, Z. Ghalamkari, \& H. Radnezhad. 2011. Efficiency of different levels of Satureja hortensis L. (Savory) in comparison with an antibiotic growth promoter on performance, carcass traits, immune responses and serum biochemical parameters in broiler chickens. African J. Biotechnol. 10: 13318-13323.

Ghazvinian, K., A.R. Seidavi, F. Laudadio, M. Ragni, \& V. Tufarelli. 2018. Effects of various levels of organic acids and of virginiamycin on performance, blood parameters, immunoglobulins and microbial population of broiler chicks. S. Afr. J. Anim Sci. 48: 961-967. https://doi. org/10.4314/sajas.v48i5.16

Gopi, M., K. Karthik, H. V. Manjunathachar, P. Tamilmahan, M. Kesavan, M. Dashprakash, B. Lingaraju Balaraju, \& M. R. Purushothaman. 2014. Essential oils as a feed additive in poultry nutrition. Adv. Anim. Vet. Sci. 2: 1-7. https://doi.org/10.14737/journal.aavs/2014.2.1.1.7

Hady, M. M., M. M. Zaki, W. Abd El-Ghany, \& M. S. Korany Reda. 2013. Assessment of the broilers performance, gut healthiness and carcass characteristics in response to dietary inclusion of dried coriander, turmeric and thyme. Int. J. Environ. Agric. Res. 2: 153-159.

Hajati, H., A. Gilani, \& S. Seifi. 2019. Scrutinizing of a liquid prebiotic on growth performance and internal organs of Japanese quail. Iranian J. Appl. Anim. Sci. 9: 557-563.

Hashemi, S. R., I. Zulkifli, M. Hair Bejo, A. Farida, \& M. N. Somchit. 2008. Acute toxicity study and phytochemical screening of selected herbal aqueous extract in broiler chickens. Int. J. Pharmacol. 4: 352-360. https://doi. org/10.3923/ijp.2008.352.360

Houshmand, M., K. Azhar, I. Zulkifli, M.H. Bejo, A. \& Kamyab. 2012. Effects of prebiotic, protein level, and stocking density on performance, immunity, and stress indicators of broilers. Poult Sci. 91: 393-401. https://doi.org/10.3382/ ps.2010-01050

Huang, Q., Y. Wei, Y. Lv, Y. Wang, \& T. Hu. 2015. Effect of dietary inulin supplements on growth performance and intestinal immunological parameters of broiler chickens. Livest. Sci. 180: 172-176. https://doi.org/10.1016/j.livsci.2015.07.015

Janardhana, V., M. M. Broadway, M. P. Bruce, J. W. Lowenthal, 
M. S. Geier, R. J. Hughes, \& A. G. Bean. 2009. Prebiotics modulate immune responses in the gut-associated lymphoid tissue of chickens. J. Nutr. 139: 1404-1409. https:// doi.org/10.3945/jn.109.105007

Jones, F. A. \& P. D. Bark. 1979. Chemical Diagnosis of Disease. 1st ed. Biomedical press, Amsterdam, New York, Oxford.

Karadas, F., V. Pirgozliev, S. P. Rose, D. Dimitrov, O. Oduguwa, \& D. Bravo. 2014. Dietary essential oils improve the hepatic antioxidative status of broiler chickens. Br. Poult. Sci. 55: 329-34. https://doi.org/10.1080/00071668.2014.891098

Krishan, G. \& A. Narang. 2014. Use of essential oils in poultry nutrition: A new approach. J. Adv. Vet. Anim. Res. 1: 15662. https://doi.org/10.5455/javar.2014.a36

Lotfi, K., A. Mahdavi, A. Jebelli Javan, H. Staji, \& B. Darabighane. 2019. Effects of different levels of resistant starch on growth performance and ileum morphology in broilers: A comparison to fructooligosaccharide and zinc bacitracin. Iranian J. Appl. Anim. Sci. 9: 315-322.

Mahboubi, M., N. Kazempour, \& M. Valian. 2013. Antimicrobial activity of natural Respitol-B and its main components against poultry microorganisms. Pak. J. Biol. Sci. 19: 10651068. https://doi.org/10.3923/pjbs.2013.1065.1068

Mašek, T., K. Starčević, \& Ž. Mikulec. 2014. The influence of the addition of thymol, tannic acid or gallic acid to broiler diet on growth performance, serum malondialdehyde value and cecal fermentation. Yeast. 5: 5-10. https://doi. org/10.1399/eps.2014.64

Mehrabi, Z., F. Firouzbakhsh, \& A. Jafarpour. 2011. Effects of dietary supplementation of synbiotic on growth performance, serum biochemical parameters and carcass composition in rainbow trout (Oncorhynchus mykiss) fingerlings. J. Anim. Physiol. Anim. Nutr. 96: 474-481. https://doi. org/10.1111/j.1439-0396.2011.01167.x

Nazzaro, F., F. Fratianni, L. De Martino, R. Coppola, \& V. De Feo. 2013. Effect of essential oils on pathogenic bacteria. Pharmaceutic. 6: 1451-1474. https://doi.org/10.3390/ ph6121451

Ohimain, E. I. \& R. T. Ofongo. 2012. The effect of probiotic and prebiotic feed supplementation on chicken health and gut microflora: a review. Int. J. Anim. Vet. Adv. 4: 135-143.

Poorghasemi, M, M. Chamani, S. Z. Mirhosseini, A. A. Sadeghi, \& A. Seidavi. 2017. Effect of probiotic and different sources of fat on performance, carcass characteristics, intestinal morphology and ghrelin gene expression on broiler chickens. Kafkas Univ. Vet. Fak. Derg. 24: 169-178.

Poorghasemi, M, A. R. Seidavi, \& A. A. A. Qotbi. 2013. Investigation on fat source effects on broiler chickens performance. Res. J. Biotechnol. 8: 78-82.

Poorghasemi, M, A. R. Seidavi, A. A. A. Qotbi, J. R. Chambers, V. Laudadio, \& V. Tufarelli. 2015. Effect of dietary fat source on humoral immunity response of broiler chickens. Eur. Poult. Sci. 79: 1-8.

Pourabedin, M., Z. Xu, B. Baurhoo, E. Chevaux, \& X. Zhao. 2014. Effects of mannan oligosaccharide and virginiamycin on the cecal microbial community and intestinal morphology of chickens raised under suboptimal conditions. Can. J. Microbiol. 60: 255-266. https://doi.org/10.1139/ cjm-2013-0899
Pournazari, M., A. A. Qotbi \& A. Seidavi, \& M. Corazzin. 2017. Prebiotics, probiotics and thyme (Thymus vulgaris) for broilers: performance, carcass traits and blood variables. Rev. Colomb. Cienc. Pecu. 30: 3-10. https://doi. org/10.17533/udea.rccp.v30n1a01

Rahimi, S., Z. Teymouri Zadeh, M. A. Karimi Torshizi, R. Omidbaigi, \& H. Rokni. 2011. Effect of the three herbal extracts on growth performance, immune system, blood factors and intestinal selected bacterial population in broiler chickens. J. Agric. Sci. Technol. 13: 527-539.

Saleh, N., T. Allam, A. A. El-Latif, \& E. Ghazy. 2014. The effects of dietary supplementation of different levels of thyme (Thymus vulgaris) and ginger (Zingiber officinale) essential oils on performance, hematological, biochemical and immunological parameters of broiler chickens. Global. Vet. 12: 736-744. https://doi.org/10.5829/idosi.gv.2014.12.06.83189

Sethiya, N. K. 2016. Review on natural growth promoters available for improving gut health of poultry: an alternative to antibiotic growth promoters. Asian J. Poult. Sci. 10: 1-29. https://doi.org/10.3923/ajpsaj.2016.1.29

Simitzis, P. E. 2017. Enrichment of animal diets with essential oils-a great perspective on improving animal performance and quality characteristics of the derived products. Medicines. 4: 35-41. https://doi.org/10.3390/ medicines 4020035

Sims, M. D., K. A. Dawson, K. E. Newman, P. Spring, \& D. M. Hoogell. 2004. Effects of dietary mannan oligosaccharide, bacitracin methylene disalicylate, or both on the live performance and intestinal microbiology of turkeys. Poult. Sci. 83: 1148-54. https://doi.org/10.1093/ps/83.7.1148

Skalická, M. \& B. Koréneková. 2016. The effects of sodium humate and aflatoxin B1 on body weight of broiler chicks. Iranian J. Appl. Anim. Sci. 6: 415-421.

Souri, H., A. Khatibjoo, K. Taherpoor, A. HassanAbadi, F. Fattahnia, \& M. Askari. 2015. Effect of Thymus vulgaris and Saturejakhuzestanicaethanolic extracts on broiler chickens' performance and immune response. Iranian J Appl Anim Sci. 5: 437-446.

Talazadeh, F. \& M. Mayahi. 2017. Immune response of broiler chickens supplemented with pediatric cough syrup including thyme exteract in drinking water against influenza vaccine. J. Herbmed. Pharmacol. 6. 33-36. https://doi. org/10.15171/ijep.2016.17

Tiihonen, K., H. Kettunen, M.H.L. Bento, M. Saarinen, S. Lahtinen, A.C. Ouwehand, H. Schulze, \& N. Rautonena. 2010. The effect of feeding essential oils on broiler performance and gut microbiota. J. Br. Poult. Sci. 51: 381-392. https://doi.org/10.1080/00071668.2010.496446

Zeng, Z., S. Zhang, H. Wang, \& X. Piao. 2015. Essential oil and aromatic plants as feed additives in non-ruminant nutrition: a review. J. Anim. Sci. Biotechnol. 6: 7-10. https://doi. org/10.1186/s40104-015-0004-5

Zhu, X., W. Liu, S. Yuan, \& H. Chen. 2014. The effect of different dietary levels of thyme essential oil on serum biochemical indices in Mahua broiler chickens. Ital. J. Anim. Sci. 13: 576-581. https://doi.org/10.4081/ijas.2014.3238 